\title{
Interview with New AMS President Kenneth A. Ribet
}

Kenneth A. Ribet received his PhD from Harvard University in 1973. He was a lecturer and assistant professor at Princeton University for five years before joining the faculty at the University of California, Berkeley, where he is professor of mathematics. His honors include election to the US National Academy of Sciences (1990) and the Prix Fermat of the Institut de Mathématiques de Toulouse (1989). Ribet took office as President of the AMS on February 1, 2017. This interview was conducted in fall 2016.

\section{Education and the AMS}

Notices: First I'd like to ask you about education. You have been devoted to teaching all your career. You won two teaching awards at UC Berkeley, one early on in your time as a faculty member there, and another one just recently, in 2013. How do you see the role of the AMS in education?

Ribet: The AMS has a big voice and can look at trends in education and make policy statements about practices we should be adopting in our classrooms. For example, many people are interested in strategies for active learning. ${ }^{1}$ Students today are uneasy going into a classroom and having a passive experience. It is a challenge to engage students and get them involved in the course and the ma-

\section{There is a real} hunger among the general public for fairly sophisticated mathematics.

terial. If the AMS has a role in shaping how people see such challenges, that would be a very positive development.

One of the committee meetings I have enjoyed the most is that of the AMS Committee on Education, which meets in Washington DC, typically every October. The committee brings in speakers who talk about educational practices.

Allyn Jackson is senior writer and deputy editor of the Notices. Her e-mail address is axj@ams .org.

${ }^{1}$ See "What Does Active Learning Mean For Mathematicians?" by Benjamin Braun, Priscilla Bremser, Art M. Duval, Elise Lockwood, and Diana White, Notices, February 2017.

For permission to reprint this article, please contact: reprint-permission@ams .org.

DOI: http://dx.doi.org/10.1090/noti1488

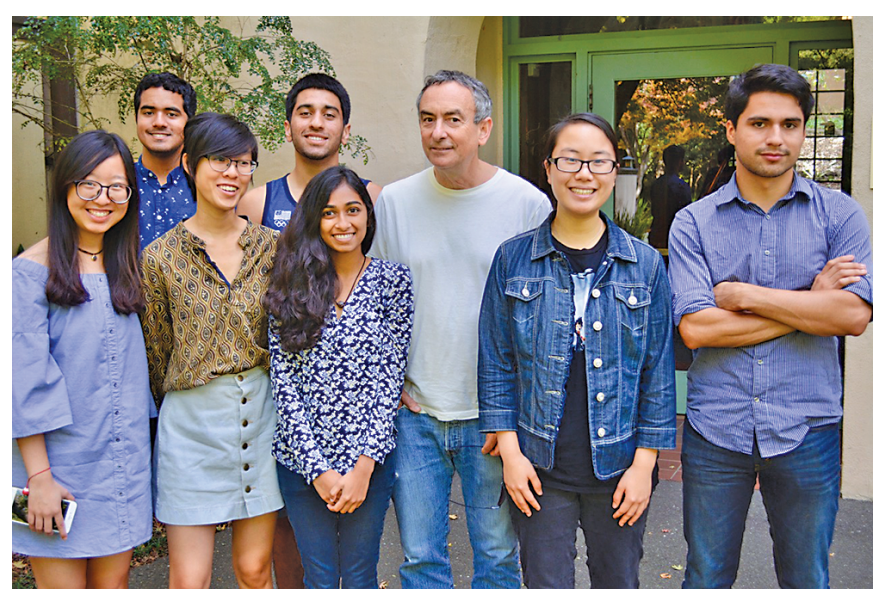

Ken Ribet (back row, third from left) often meets for breakfast with groups of students, such as this one that met with him in November of last year (from left to right): Xuefei Lei, Rahul Malayappan, Aileen Ho, Karam Samplay, Gauri Powale, Emily Hsiao, and Genaro Hernandez Salgado.

It's thoroughly illuminating. I am by training a completely traditional teacher. Nonetheless, the exposure that I've had to these different points of view has influenced the way that I interact with my students.

Currently I am teaching a class where the enrollment is about 375. It's my job to engage with those students as well as I can. I try to make sure the students come to the lectures-I call them class meetings instead of lectures-and to make them as interactive as possible. I run around the room and solicit questions, I make an effort to call students by name when they raise their hands. This seems to limit absences and eliminate texting and web surfing in class. 
Notices: You said students don't want a passive experience in the classroom. Is that very different from when you first started at Berkeley?

Ribet: When I first started at Berkeley, students would go into this old room with lots of wood and chalkboards and sit there. The professor would lecture, and the students would take notes. The experience was completely scripted. No one questioned the procedure. Now, students get input through a constant barrage of media-through their tablets and phones and laptops. It's perceived as cool to ditch class and try to make up for it at the very last minute by binge-watching recorded lectures.

In my courses, I look for ways to interact with the students informally, to get a sense of what would appeal to them, what reaches them. I try to make mathematics something that they can relate to.

\section{Public Awareness of Mathematics}

Notices: Andrew Wiles's proof of Fermat's Last Theorem [featured in this issue of the Notices], to which your work contributed crucially, attracted huge attention from the general public. Since that time, the public's interest in mathematics has grown quite a bit. Why? And what role can the AMS play here?

Ribet: I was in Cambridge, England, in June 1993, when Wiles announced a proof of Fermat's Last Theorem. When I returned to Berkeley, people at MSRI [Mathematical Sciences Research Institute]-Bill Thurston, Lenore Blum, and others-suggested doing a public event around FLT. There was a huge gathering in San Francisco where a group of mathematicians-I was one of them, as were Karl Rubin, Bob Osserman, Lenore Blum, and others-got up in front of 2,000 people and talked about Wiles's proof. ${ }^{2}$ We had a post-event discussion at MSRI the next week, and Thurston said: "This is great. We have to do more things like this. What do we do now?" I remember being skeptical. I thought the proof of FLT was such a singular development that there would be no way to maintain the public's interest in research mathematics. Now, over twenty years later, it's been incredibly gratifying to see the growth in interest in FLT and many other wonderful mathematical results.

Recently I watched a Numberphile ${ }^{3}$ video on a combinatorial problem called the Josephus problem. The video featured a young mathematician named Daniel Erman. He explained something that is fairly sophisticated, using induction and binary expansion. At the time I watched it, the number of views of that video was up to about a quarter of a million, and it had been out only a few days. That's one of many indications of a real hunger among some segments of the general public for fairly sophisticated mathematics.

\footnotetext{
${ }^{2}$ See "Fermat Fest Draws a Crowd," by Allyn Jackson, Notices, October 1993.

${ }^{3}$ Sponsored by MSRI, Numberphile (www. numberphi 1e.com) is a website featuring videos made by Brady Haran, in which mathematicians talk about mathematical ideas and concepts. The videos are personal, humorous, quirky, insightful, and a lot of fun.
}

I think we mathematicians have gotten much better at presenting ourselves to the outside world. Mathematicians, who fifty years ago were solitary figures pacing the floor, are interacting with people outside their immediate circle. It's perhaps part of the general trend where mathematics has become more collaborative. People are more used to explaining themselves to others who are not necessarily "living inside their brains," as my wife says. More and more mathematicians have taken up positions in business and industry and government, where they have to explain their work to colleagues who have no mathematical training. And they have to listen to descriptions of problems that are fundamentally mathematical, from people who don't view those problems in mathematical terms.

\section{The world of math is much less orderly than it used to be.}

There is a related trend. More and more mathematics is applied. Thirty years ago, if you talked about applied mathematics, it meant differential equations and fluid dynamics. Nowadays, applied math can be anything-number theory, or combinatorics, or algebraic geometry applied to robotics. There is a wonderful report, Mathematical Sciences in 2025 [National Academy Press, 2013], that talks about all the ways in which math has influenced daily life. Quaternions in electric toothbrushes and video games - this is just great! Obviously we have something to offer to the outside world. The AMS is right at the center of the picture.

Notices: What do you think the AMS can do to capitalize on this upswell of public interest in math?

Ribet: The AMS is part of the reason there is this public interest. We have the wonderful AMS Public Awareness Office, which is tweeting all the time and has a big presence on Facebook. We also have the AMS office in Washington DC, which helps communicate about mathematics with people on Capitol Hill. ${ }^{4}$ It's one of the fundamental activities of the AMS now, to look beyond the immediate community of academic mathematicians.

\section{New Generations, New Technologies}

Notices: You mentioned in your candidacy statement for AMS president that technology is bringing rapid changes and unprecedented opportunities to mathematics. Can you say more about what you mean by that, what kind of technology you are referring to?

Ribet: It's clear that one of the challenges for the AMS now is to continue to maintain its relevance in a context where young mathematicians are using technology to share and gather information with less of the formal structure that older mathematicians like myself are used

\footnotetext{
${ }^{4}$ Karen Saxe, who started as director of the AMS Washington Office in January of this year, was interviewed by Notices associate editor Harriet Pollatsek in the December 2016 issue.
} 
to. People ask questions and get answers on MathOverflow. Many people feel that the definitive version of a manuscript is the one deposited on arXiv. Traditional journals are sometimes seen as unimportant. People often bypass MathSciNet ${ }^{\circledR}$ when trying to get information. They collaborate through blogs. The world of math is much less orderly than it used to be. When I was a young mathematician, I would run to the library every month to look at the latest printed volume of Math Reviews. I would wait for the Notices and the Bulletin and the Abstracts to arrive in my mailbox. I would go to the library to look at the latest issues of Inventiones, the Duke Mathematical Journal, and Annals of Math. Now, many results are disseminated without that structure.

Notices: What can the AMS do to make itself relevant to young people who are developing as mathematicians in this very different environment?

Ribet: An initiative ongoing for the past three or four years, through strategic planning, aims to reinvent the AMS in some sense-to make sure it remains relevant and to meet changing needs of younger mathematicians. The AMS has carried out interviews and surveys to find out what mathematicians think of and need from the AMS. It's hard for me to summarize the findings in a few short sentences, but it is clear that in the next few years, the AMS will evolve in lots of ways in response to this strategic planning. The books will look different. There will be new journals. The AMS will respond to what we have heard from our membership.

\section{Preparing for Careers in Business, Industry, Government}

Notices: What other challenges face the AMS?

Ribet: One challenge is that the majority of the young people who are in graduate programs or are new $\mathrm{PhDs}$ will pursue careers outside of academia. It's important for the AMS to make people aware of this reality and to prepare them for transitions they'll need to make, to ensure that graduate programs are providing good preparation. ${ }^{5}$

My wife, Lisa Goldberg, is a mathematician who works in industry as a financial economist and is on the faculty of UC Berkeley in economics and statistics. Graduate students come into those departments, and from Day One, the majority of them are thinking about jobs in industry, biotech, consulting, government. Very few of them consider that their goal is to be like their professors. In mathematics, which is a neighboring discipline, it's completely different. If you talk to a first- or second-year graduate student in mathematics, you find that person's goal is to, say, transform the study of Banach algebras through the use of derived algebraic geometry. With few exceptions, they think in terms of academic careers. What happens is that a majority of those people, soon after their PhDs, realize that they would be a lot happier in a business or industry or government setting. They

\footnotetext{
${ }^{5}$ See "Math PhD Careers: New Opportunities Emerging Amidst Crisis," by Yuliy Baryshnikov, Lee DeVille, and Richard Laugesen in this issue of the Notices.
}

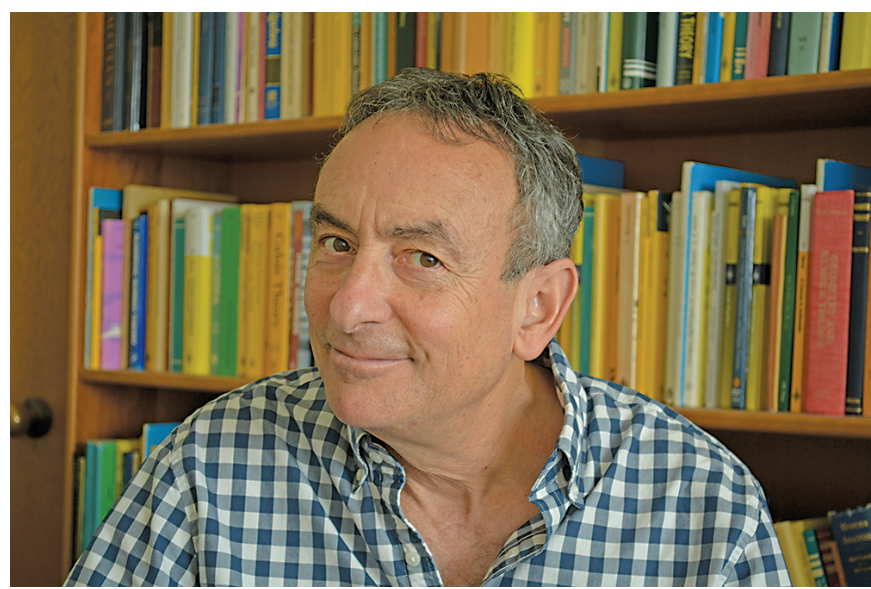

Ken Ribet.

often scramble to prepare themselves for such careers by increasing their programming skills or learning basic statistics.

People who make this transition report back and say, "It's fantastic, I should have done this from the beginning of my graduate career, this is a much more rewarding experience than I imagined when I started on that road." At every JMM [Joint Mathematics Meetings] there is a panel about industry jobs, and the panelists are just glowing, saying how wonderful their work is. But somehow, the word is not percolating to the level of first-year graduate students, who are still very much of the mindset that they want to be exactly like their professors. I think the AMS can have an important role in changing the mindset.

\section{Memories of Serge Lang}

Notices: You were a great friend of Serge Lang. ${ }^{6}$ He resigned from the AMS about ten years before his death. What do you think he would have said about your becoming AMS president?

Ribet: Serge had an expression he would use to describe, say, a speech by a prominent university administrator or some other august figure. He would refer to these speeches as "big time bullshit." This was one of his favorite descriptors, and he used it a lot. Maybe twentyfive years ago, I was asked to run for the AMS Council. Serge was in Berkeley every summer, and he was here when I wrote my candidate's statement. I showed it to Serge and asked him what he thought. He shook his head and looked very displeased. Using Serge's expression, I said, "Big time bullshit?" And he said, "Not big time"!

I lost that election. More recently, I was asked again to run for the Council. I had just been to an informal gathering of the Council after one of its long meetings, and I had an incredibly positive impression of the whole enterprise. I loved the people and what they were doing. I agreed enthusiastically to make a second run for the

\footnotetext{
${ }^{6}$ Serge Lang (1927-2005) was a French-born mathematician who spent most of his career at Yale University. Read more about him in the obituary that appeared in the May 2006 issue of the Notices.
} 
Council. I was elected to the Council and was later chosen for the Executive Committee. Then I was asked to run for president-and I was elected.

I think that Serge, despite the fact that he had negative views of various things, had a great deal of respect for people's passion. He liked me very much, and he respected me. If he were around today and saw that I was passionate about working for the AMS, he would respect that.

Just to summarize what happened with Serge's resignation from the AMS: In the 1970s, Serge started his "file-making," in which he developed the theme that there were systematic abuses of power by people at the top of the scientific establishment who would quash opposing views if those views conflicted with their own ambitions. He thought that HIV/AIDS was one of those subjects where the people in power were quashing opposing viewpoints. What prompted Serge's resignation from the AMS was one particular article in the Notices about the mathematics of HIV. ${ }^{7}$ This was most unfortunate, because it was an abrupt break with an organization that he had supported through his whole career, over one particular incident. So it was certainly not the case that Serge was opposed to the AMS in general.

Notices: He was an interesting character.

Ribet: He really was. I still have stacks of his files in my office. When my office was renovated, I had a great deal of fun filling up barrels with paper to be recycled or shredded. But I kept all of Lang's files.

\section{Budding Sommelier?}

Notices: In 1988 you were named Vigneron d'Honneur de St. Emilion. What does this mean?

Ribet: I have been interested in wine ever since I was a graduate student and then a Sloan Fellow in Paris. From the beginning, I had very strong opinions about the quality of wines. I could discern all kinds of tastes in wines and was completely impassioned. In Paris, through a chance encounter, I met someone who was a sommelier, and I ended up becoming an affiliate member of the Association des Sommeliers de Paris. Once I was on their mailing list, I got invited to a ton of industry tastings in Paris. There would be five or six per week. Of course I didn't go to every tasting, but I went to quite a few of them. They would typically be held at $4 \mathrm{pm}$ or $5 \mathrm{pm}$ in the afternoon, between the two meal services at restaurants. It was a fantastic education. I became acquainted with every single alchoholic product on the French market at the time-this was the late 1980s.

During this period, some of the mathematicians in Bordeaux felt that it was incredibly unusual to have a professional mathematician who also had a professional education in wine. So they brought my name to the attention of the people in St. Emilion who have an annual induction ceremony for honorary winemakers. Most of these winemakers are wine critics from the newspapers, or industry figures-people who have served in the wine

\footnotetext{
7 "Using Mathematics to Understand HIV Immune Dynamics," Notices, February 1996; see also Lang's response on receiving the 1999 Steele Prize for Exposition, Notices, April 1999.
}

profession for many years. Somehow, they snuck my name in. I got to wear a strange cloak and participate in all sorts of amazing rituals. I really felt like an impostor! After the induction ceremony, we were invited to a seven-course banquet, and for every course they would bring out about a dozen St. Emilion wines.

Notices: A dozen for each course?

Ribet: A dozen for each course. There were many glasses on the table, and I came close to sampling all of the wines. A few years later I went back to one of their banquets with my wife, who was also completely amazed. I've
When I was a graduate student, I had a moment of doubt and thought about becoming a disc jockey. never had anything comparable in my experience.

I no longer have the palate of the professional, and I no longer follow everything that's available, but I still have pretty strong preferences when looking at wine lists in restaurants. I typically go for wines that are exceptional values in a given price range.

Notices: Did you think about becoming a sommelier?

Ribet: I never thought about becoming a sommelier. But when I was a graduate student, I had a moment of doubt: "Why am I doing this? I'll never do any research. Even if I write a thesis, it won't be very good." I thought about becoming a disc jockey, because when I was an undergraduate I spent all my time on the campus radio. So I turned to my friends who had gone into the radio industry and asked if they had a job for me. They said, "You're really good in math, why don't you stick with that? The radio industry is pretty hard." So I decided to try again.

At the end of my graduate career, I was very surprised that people were actually offering me jobs. I thought, "Who cares? I'm doing this thing with abelian varieties, it's not likely to attract any attention."

Notices: So everybody goes through those doubts.

Ribet: Absolutely. Doing mathematics is just a permanent situation of being wracked with self-doubt. Where is my next theorem? Am I still any good? Is this proof really right? Will anyone care about it?

Notices: Those are comforting words for the young people entering the profession. They know they are not alone.

Ribet: You bet!

Notices: And will you be in charge of the wine at the AMS banquet?

Ribet: I'll be glad to help if they need me.

\section{Photo Credits}

Photo of Ken Ribet with students is courtesy of Jerry

Fowler.

Photo of Ken Ribet is courtesy of Gauri Powale. 